\title{
Giant Solitary Plasmacytoma of Skull: A Case Report
}

\author{
Islam KMT ${ }^{1}$, Jahan $\mathrm{N}^{2}$, Bhattachariya $\mathrm{R}^{2}$, Halder $\mathrm{R}^{2}$, Hafiz $\mathrm{AM}^{3}$, Alam $\mathrm{S}^{4}$, Haque $\mathrm{M}^{5}$, \\ Hossain ATMM ${ }^{6}$, Barua $\mathrm{KK}^{6}$
}

\begin{abstract}
:
Plasmacytoma is a tumor arising from plasma cell, which mainly grows within soft tissue or within axial skeleton, when it is present as a discreet solitary mass it is called as solitary plasmacytoma $\&$ it is rare, we report a 46 years male, presented to us with the complaints of painless swelling in the left front parietal region which is about $8.6 \times 6.5 \mathrm{~cm}$ in diameter, Magnetic resonance imaging revealed an extra axial mass in fronto parietal region with overlying bone destruction mimicking meningioma with bony erosion, we did frontoparietal craniectomy and complete resection of tumor with bone margin subsequent cranioplasty also done, histopathology of which revealed plasmacytoma, after that we did urinary bence jones protein which was negative.
\end{abstract}

Bang. J Neurosurgery 2019; 8(2): 115-118

\section{Introduction:}

Plasmacytoma is malignant proliferation of plasma cell, mainly arise from proliferation of a single clone of B lymphocyte, $3 \%$ of which present as solitary lesion ${ }^{1}$. The international myeloma working group lists three types of plasmacytoma: solitary plasmacytoma of bones, extramedullary plasmacytoma \& multiple plasmacytoma. Solitary plasmacytoma occurs as lytic lesion.

An osteolytic plasmacytoma lesion in skull with no systemic involvement is extremely rare. ${ }^{2}$ Multiple myeloma, extramedullary plasmacytoma \& solitary bone plasmacytoma all are the three subgroup of

1. K.M. Tarikul Islam, Associate Professor, Department of Neurosurgery, Bangabandhu Sheikh Mujib Medical University, Dhaka.

2. Nowshin Jahan, Razib Bhattachariya, Rathin Halder, Resident, MS Neurosurgery, Department of Neurosurgery, Bangabandhu Sheikh Mujib Medical University.

3. Ahsan Md. Hafiz, Medical Officer, Department of Neurosurgery, Uttara Adhunik Medical College, Dhaka.

4. Shamsul Alam, Assistant Professor, Department of Neurosurgery, Bangabandhu Sheikh Mujib Medical University, Dhaka.

5. Moududujl Haque, Associate Professor, Department of Neurosurgery, Bangabandhu Sheikh Mujib Medical University, Dhaka.

6. ATM Mosharef Hossain, Kanak Kanti Barua, Professor, Department of Neurosurgery, Bangabandhu Sheikh Mujib Medical University, Dhaka.

Address of Correspondence: Dr. K.M. Tarikul Islam, Associate Professor, Department of Neurosurgery, Bangabandhu Sheikh Mujib Medical University, Dhaka, Mobile: 01824-636201, e-mail: dr.tarik_2007@yahoo.com plasma cell tumor. ${ }^{3}$ We present a case of plasmacytoma present in frontoparietal region.

\section{Case report:}

A 77 years male got admitted us with complaints of gradual enlargement of a painless swelling on his vertex for one year, on examination we found a painless mass in left frontoparietal region measuring about $8.5 \times 6.4$ $\mathrm{cm}$ in diameter (Figure- 1), which was firm in consistency, not mobile, fixed with underlying \& overlying structure, on general physical examination no other abnormality detected, neurological examination was also normal. he has no significant past medical or surgical illness. On MRI of brain revealed $a$ is to hypointense extra axial lesion involving the left frontoparietal region measuring about $8 \times 6 \mathrm{~cm}$ causing mass effect over the brain parenchyma (Figure-2), On intravenous gadolinium showed strong enhancement of the lesion (Figure-3). CT scan of brain revealed a lytic lesion in left frontoparietal region causing a bone defect (Figure-4). Magnetic resonance venogram displayed the superior sagittal sinus is compressed by the tumor, complete blood count all are within normal range. Our differential diagnoses were meningioma or metastasis. So we did all metastatic work up eg. thyroid scan, usg of whole abdomen and tumor marker but all were normal, $\mathrm{He}$ underwent craniectomy. Peroperative tumor was found to involve the subcutaneous tissue, bone and duraTtumor was moderately vascular, total removal of tumor with involved bone and part of dura (Figure- 5). Cranioplasty was done. Histopathology revealed plasmacytoma. Postoperative period was uneventful, as there was no other site of lytic lesion and we removed tumor in enbloc, so radiotherapy was not performed. 


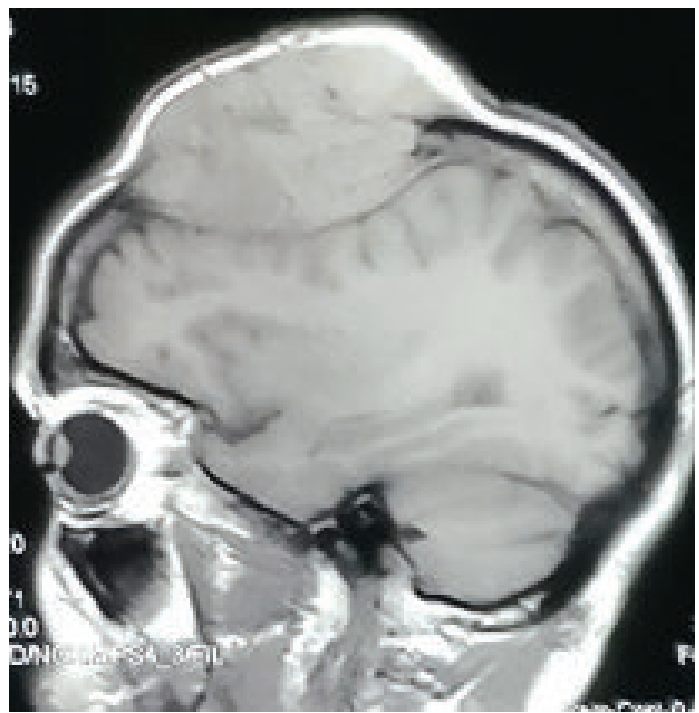

Fig.-1: Mass over left. frontoparietal region

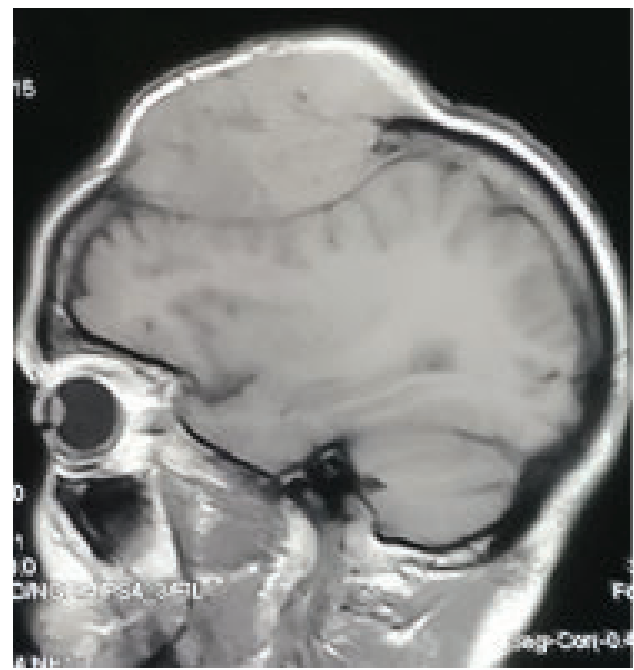

Fig.-3: Sagittal view \& Coronal view of contrast MRI
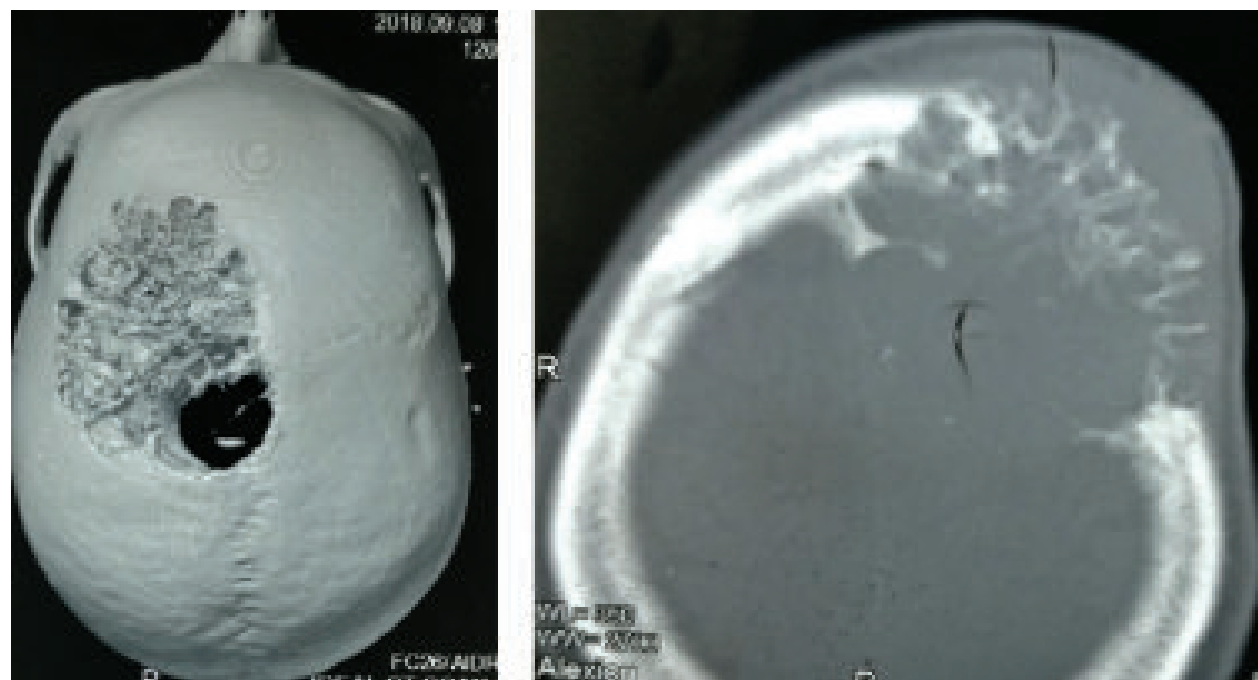

Fig.-4: CT scan of brain in bone window showing erosion at left frontoparietal region.
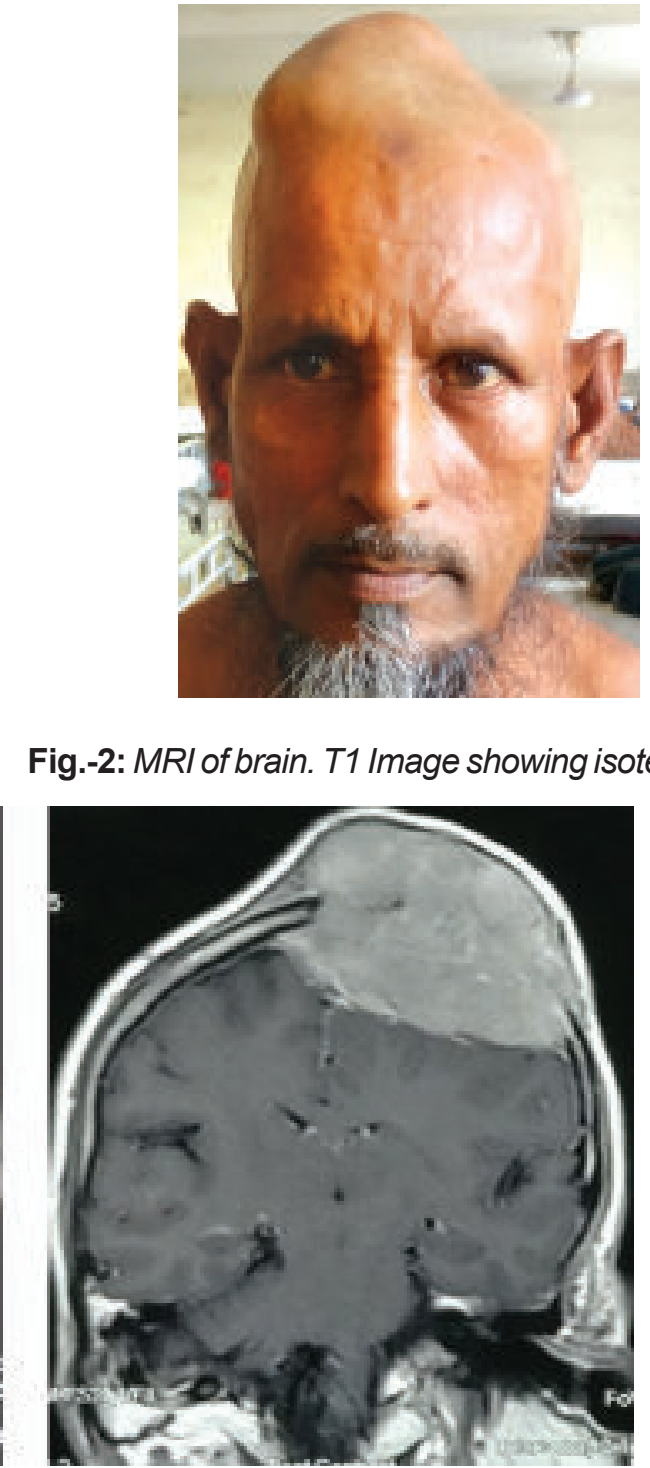

Fig.-2: MRI of brain. T1 Image showing isotense lesion 

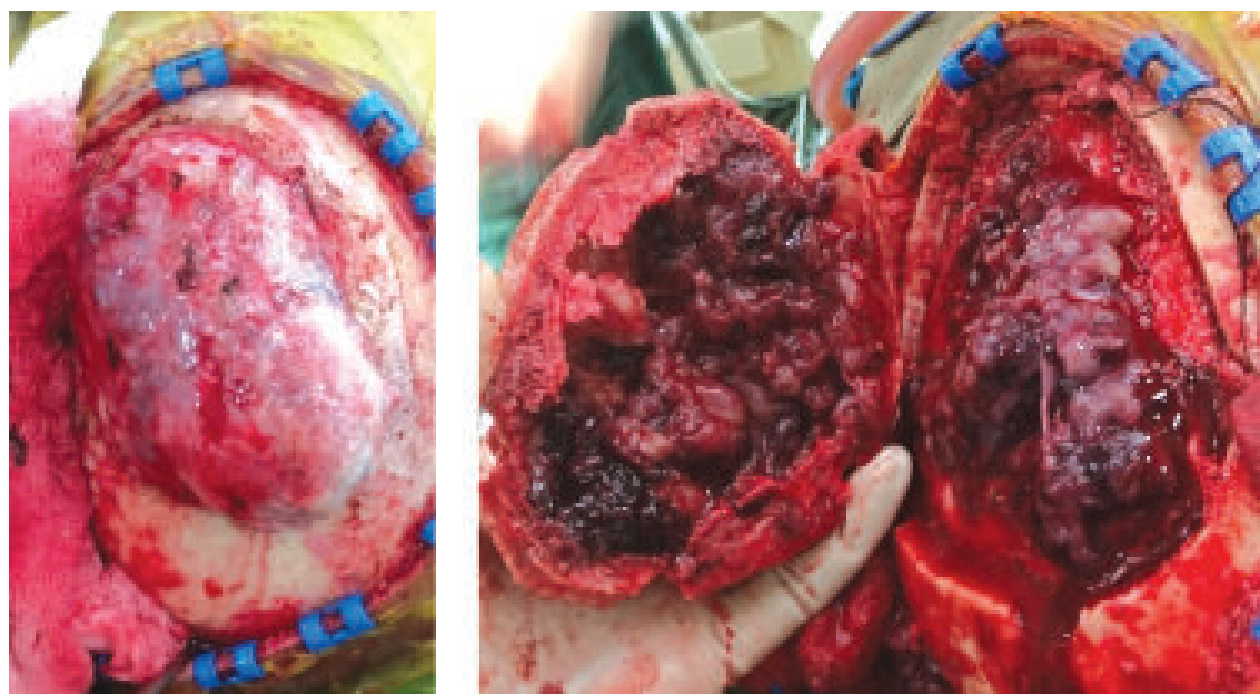

Fig.-5: Per-operative photo: After careful dissection of skin and craniectomy tumor found attached with underlying bone and dura and tumor was removed enbloc

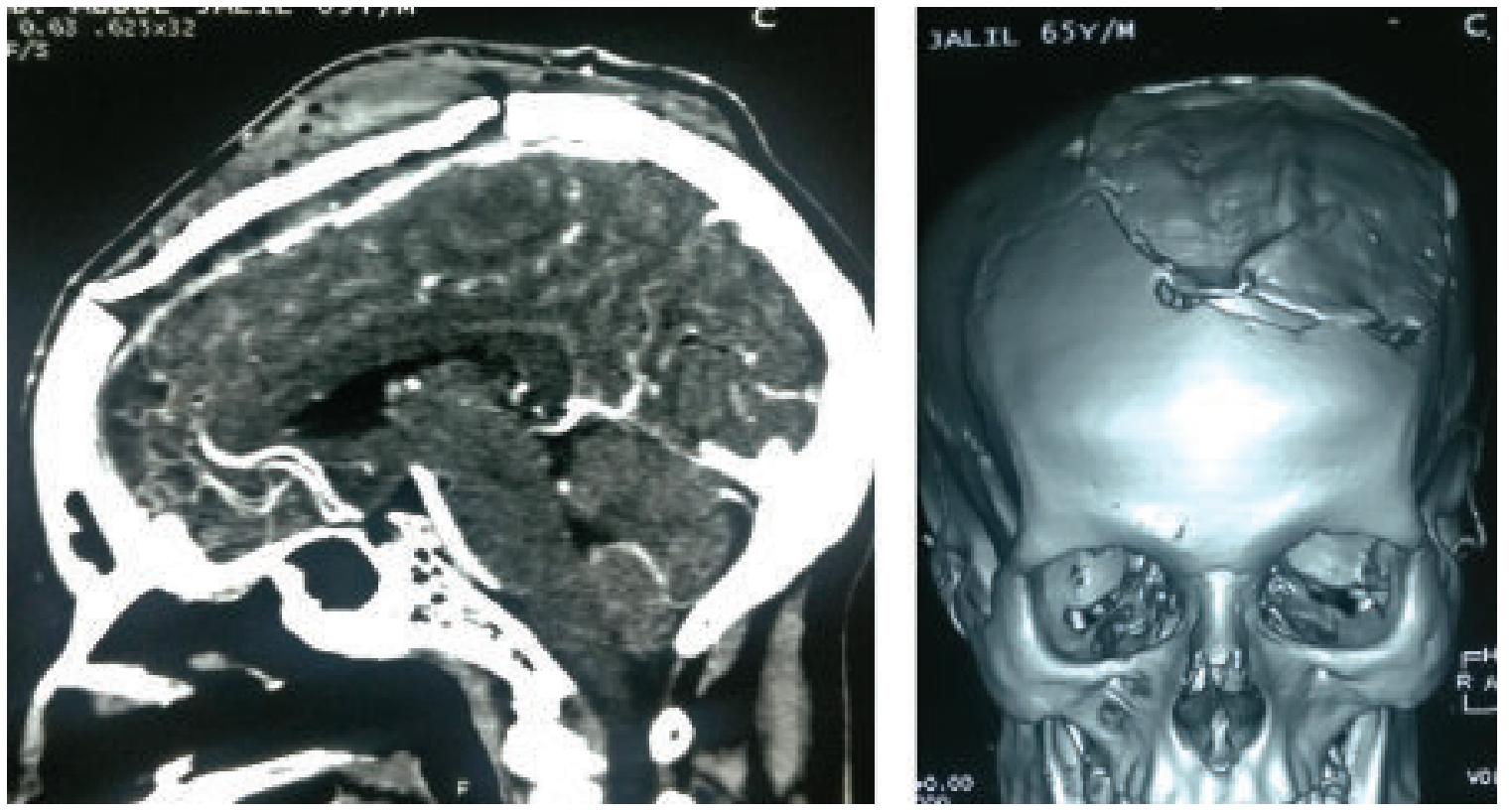

Fig.-6: Pos-operative CT scan of brain showing no residual tumor and acceptable cranioplasty.

Table-I

Patients with solitary plasmacytoma of skull received enbloc removal including cranioplasty and duroplasty published in literature.

\begin{tabular}{|c|c|c|c|c|c|c|c|}
\hline Study & $\begin{array}{l}\text { Age \& } \\
\text { gender }\end{array}$ & $\begin{array}{l}\text { Location } \\
\text { of tumor }\end{array}$ & surgery & cranioplasty & Radio-therapy & Follow up & recurrence \\
\hline Arienta et al.,1987 [7] & $64, \mathrm{~F}$ & Parietal & GTR & Yes (titanium mesh) & No & 3 years & No \\
\hline Du Preez et al.,1991[6] & $30, F$ & Frontotemporal & GTR & Yes & No & 1.5 & No \\
\hline Barone et al.,1992[8] & $55, \mathrm{~F}$ & Frontal & GTR & Yes autograft & No & 9months & No \\
\hline Madsuda et al.,1996[9] & $55, \mathrm{~F}$ & Temporal & GTR & Yes autograft & Yes & 2 years & No \\
\hline Tanaka et al.,1998[10] & $55, \mathrm{M}$ & Frontal & GTR & Yes & Yes & 7 months & No \\
\hline Gürbüz et.ai.,2013[11] & $63, M$ & parietooccipital & GTR & Yes autograft & Yes & & No \\
\hline Mankotia et al.,2017[12] & $36, \mathrm{M}$ & Frontal & GTR & Yes cement & Yes & 3 months & No \\
\hline Kuo et al.,2018[4] & $40, \mathrm{M}$ & parietooccipital & GTR & Yes cement & No & 1 year & No \\
\hline
\end{tabular}




\section{Discussion:}

Plasma cell tumor are divided in three type solitary plasmacytoma of bone (SPB), extramedullary plasmacytoma \& multiple myeloma. Multiple myeloma is systemic disease which involved multiple osteolyticlesions, atypical plasma cell in biopsy , amyloid deposit \& abnormalities in immunoglobulin production, and the others are local form of plasma cell tumor, According to Bataille and Sany, the diagnostic criteria for SPB include an isolated tumor composed of malignant plasma cells; absence of other lesions on skeletal radiographic survey; absence of plasmacytosis in the bone marrow, absence of anemia, hypercalcemia, or renal involvement \& the Vertebrae and pelvic bones are mostly involved by SPB. ${ }^{3}$ Solitary plasmacytoma of skull is rare disease and considered to be curable with resection \& radiotherapy. ${ }^{4}$ Due to its rarity most of the time preoperatively it is misdiagnosed as meningioma or metastasis. As compared to SPB the prognosis of solitary plasmacytoma of skull is good if it is diagnosed on strict criteria. ${ }^{1}$ So making the appropiate diagnosis is necessary for further management \& follow up, though from some literature they think that solitary plasmacytoma is the initial presentation of multiple myeloma with progression of time this may convert into multiple myeloma. ${ }^{5}$

We go through published literature [Table:1(4,6-12)] of patients diagnosed as a case of solitary plasmacytoma of skull received enbloc removal of tumor including cranioplasty. All of those patients are histopathologically proven plasmacytoma of skull among them four patients receive only surgery, no post operative radiotherapy or chemotherapy, and four patients received surgery along with post operative radiotherapy, and on follow up among them seven patient has no recurrence except one patient whom post operative follow up is not avialable.

Radiotherapy is the definitive treatment for solitary plasmacytoma of bone, surgery along with radiotherapy is the treatment of choice based on tumor location and type of removal of tumor, chemotherapy is not needed until there is systemic involvement as like multiple myeloma. ${ }^{4}$ if there is gross total resection of tumor incase of isolated local tumor radiotherapy is needed or not is still in quary, but as sometimes solitary plasmacytoma is the initial presentation of multiple myeloma regular follow up is necessary in all cases.

\section{Conclusion:}

Isolated solitary plasmacytoma is a very rare tumor, enbloc tumor removal with removal of involved bone and dura upto macroscopic healthy margin with cranioplasty and duroplasty is a treatment option as histopathology report reveals margin is free from tumor, so no radiotherapy is required but regular follow up should be carried out.

\section{References:}

1. Gill MK, Makkar M, Bains SP. Solitary plasmacytoma of skull: a rare cytological diagnosis. Journal of clinical and diagnostic research: JCDR. 2013 Aug;7(8):1702.

2. Dong L, Zhang X, Zhang H, Song R, Gu X, He L. Solitary plasmacytoma of the skull: Two case reports. Oncology letters. 2013 Feb 1;5(2):479-82.

3. Lae ME, Vencio EF, Inwards CY, Unni KK, Nascimento AG. Myeloma of the jaw bones: a clinicopathologic study of 33 cases. Head \& Neck: Journal for the Sciences and Specialties of the Head and Neck. 2003 May;25(5):373-81.

4. Kuo Y, Huang W, Wu J. Surgical Treatment for a Giant Solitary Plasmacytoma with Skull Erosion. Cureus. 2018 Nov 1;10(11)

5. Yang X, Ma M, Li L, Zhang Y. Case Report Solitary plasmacytoma of the skull: case report. Int J ClinExpPathol. 2017;10(6):7112-5.

6. Du Preez JH, Branca EP. Plasmacytoma of the skull. Neurosurgery. 1991 Dec 1; 29(6):902-6.

7. Arienta C, Caroli M, Ceretti L, Villani R: Solitary plasmacytoma of the calvarium: two casestreated by operation alone. Neurosurgery. 1987; 21:560-563.

8. Barone CM, Jimenez DF, Argamaso RV: Solitary calvarial plasmacytoma. J Craniofac Surg.1992; 3:108-112.

9. Gurbuz MS, Akmil MU, Akar E, Aker FV. Solitary plasmocytoma of the skull. BMJ Case Rep.2013.

10. Mankotia DS, Borkar SA, Kaur K, Suri V, Sharma BS. A rare case of giant solitary calvarial plasmacytoma: can it grow bigger than this?.Neurol India. 2017; 65:420-422.

11. Matsuda M, Nakazawa T, Kizuki H, Matsumura K, Nakasu S, Handa J. Solitary plasmacytomaof the skull vault-case report. Neurol Med Chir (Tokyo). 1996; 36:388-392.

12. Tanaka M, Shibui S, Nomura K, Nakanishi Y. Solitary plasmacytoma of the skull: a case report, 1998. 